NBER WORKING PAPER SERIES

\title{
OPTIMAL AWARDS AND PENALTIES WHEN \\ THE PROBABILITY OF PREVAILING \\ VARIES AMONG PLAINTIFFS
}

\author{
A. Mitchell Polinsky \\ Daniel L. Rubinfeld
}

Working Paper No. 4507

\section{NATIONAL BUREAU OF ECONOMIC RESEARCH \\ 1050 Massachusetts Avenue \\ Cambridge, MA 02138 \\ October, 1993}

Polinsky's research was supported by the John M. Olin Program in Law and Economics at Stanford Law School. Rubinfeld's research was supported by the National Science Foundation and the Center for Advanced Study in the Behavioral Sciences. An earlier and substantially different version of this article appeared as "Optimal Awards and Penalties When Some Suits are Frivolous," Working Paper No. 93, John M. Olin Program in Law and Economics, Stanford Law School, June 1992. We received helpful comments on the earlier version from Douglas Baird, Keith Hylton, Louis Kaplow, Michael Meurer, Thomas Miceli, Ivan Png, William Rogerson, Steven Shavell, Edward Sherry, Kathryn Spier, and participants in a number of seminars. This paper is part of NBER's research program in Law and Economics. Any opinions expressed are those of the authors and not those of the National Bureau of Economic Research. 


\title{
OPTIMAL AWARDS AND PENALTIES WHEN \\ THE PROBABILITY OF PREVAILING \\ VARIES AMONG PLAINTIFFS
}

\begin{abstract}
This article derives the optimal award to a winning plaintiff and the optimal penalty on a losing plaintiff when the probability of prevailing varies among plaintiffs. Optimality is defined in terms of achieving a specified degree of deterrence of potential injurers with the lowest litigation cost. Our main result is that the optimal penalty on a losing plaintiff is positive, in contrast to common practice in the United States. By penalizing losing plaintiffs and raising the award to winning plaintiffs (relative to what it would be if losing plaintiffs were not penalized), it is possible to discourage relatively low-probability-of-prevailing plaintiffs from suing without discouraging relatively high-probability plaintiffs, and thereby to achieve the desired degree of deterrence with lower litigation costs. This result is developed first in a model in which all suits are assumed to go to trial and then in a model in which settlements are possible.
\end{abstract}

\author{
A. Mitchell Polinsky \\ Stanford Law School \\ Stanford University \\ Stanford, CA 94305 \\ and NBER
}

\author{
Daniel L. Rubinfeld \\ Department of Economics \\ University of California, Berkeley \\ Berkeley, CA 94720
}




\section{Introduction}

This article derives the optimal award to a winning plaintiff and the optimal penalty on a losing plaintiff when the probability of prevaling varies among plaintiffs. Optimality is defined in terms of achieving a specified degree of deterrence of potential injurers with the lowest 1itigation cost. Our main result is that the optimal penalty on a losing plaintiff is positive, in contrast to common practice in the United States. This result is developed first in a model in which all suits are assuned to go to trial (Section 2) and then in a model in which settlements are possible (Section 3). We conclude with some observations about two related topics - the British rule for allocating litigation costs and Becker's theory of public enforcement (Section 4).

The essence of our argument is that if losing plaintiffs are not penalized, then it is possible to impose a penalty and raise the award so as to reduce the value of suits for relatively low-probability-of-prevailing plaintiffs while at the same time increase the value of suits for relatively high-probability-of-prevailing plaintiffs. This is feasible because, by definition, low-probability plaintiffs have a lower probability of winning at trial, or equivalently, a higher probability of losing, than high-probability plaintiffs. As a result, imposing a penalty will disadvantage low-probability plaintiffs more than high-probability plaintiffs, while raising the award will

1 Our article is the first to demonstrate the desirability of a general policy of imposing a penalty on a plaintiff if he loses. Of related interest, however, are articles that evaluate alternative rules for allocating litigation costs, including making a losing plaintiff pay the defendant's legal fees. For two recent examples, see Gravelle (1993) and Bebchuk and Chang (1992). (We show in Section 4 that the optimal penalty may differ substantially from the defendant's legal fees.) Also of interest are articles that consider the use of penalties to control frivolous suits. See, for example, Katz (1990, PP. 19-20) and Polinsky and Rubinfeld (1993). 
benefit high-probability plaintiffs more than low-probability plaintiffs.

Reducing the value of suits for low-probability plaintiffs will cause fewer of them to sue, thereby saving litigation costs, while raising the value of suits for high-probability plaintiffs increases the defendant's expected payment, thereby allowing deterrence to be maintained.

\section{The Basic Analysis}

A risk-neutral injurer engages in conduct that causes harm to one of a number of risk-neutral potential victims. (We will use the terms "injurer" and "defendant" interchangeably, and similarly for "victim" and "plaintiff.") The probability of prevailing at trial varies among potential victims. ${ }^{2}$ Each one knows his probability of prevailing, but the injurer knows only the distribution of the probabilities among potential plaintiffs.

In the basic analysis, all suits are assumed to go to trial. If the plaintiff wins, he receives an award from the defendant. If the plaintiff loses, he pays a penalty to the defendant. Each side bears its own trial costs.

The following notation will be used:

$p=$ probability that the plaintiff will prevail at trial;

$f(p)=$ density of $p$ among potential plaintiffs;

$x$ - award paid to the plaintiff from the defendant if the plaintiff prevails at trial $(x \geq 0)$;

2 The probabllity might vary because plaintiffs differ in their ability to marshall evidence about issues relating to causality or fault. In products liability cases, for example, some victims may have kept packing material or a receipt as proof of purchase, while others may not have. In accident cases, evidence about fault sometimes may be destroyed and sometimes may not be. 


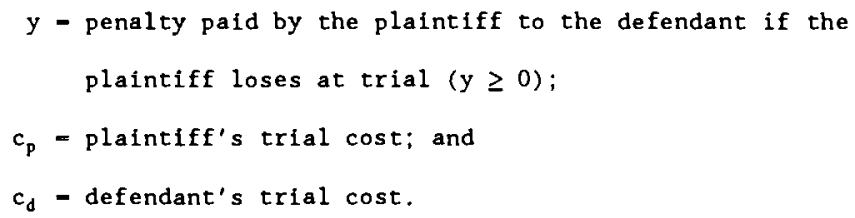

The population of potential plaintiffs is normalized to be unity.

A victim will file a suit if the expected value of the trial outcome exceeds his trial cost. Let

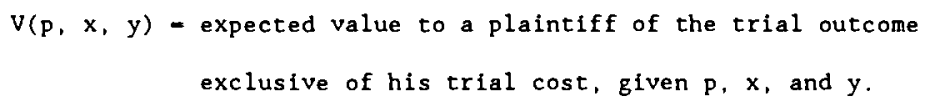

Note that

$$
v(p, x, y)-p x-(1-p) y
$$

We assume that $x>c_{p}$, so that if the probability of prevailing is sufficiently high, a victim will bring a suit (otherwise a victim would not sue even if he were certain to win). Also, if the probability of prevailing is low enough, a victim will not find it worthwile to sue. Let

$\hat{p}(x, y)$ - value of the probability of prevailing below which a victim will not sue and above which he will sue, 3 where $\dot{p}(x, y)$ is defined by:

$$
\mathrm{V}(\dot{\mathrm{p}}, \mathrm{x}, \mathrm{y})-\hat{\mathrm{p}} \mathrm{x}-(1-\hat{\mathrm{p}}) \mathrm{y}-\mathrm{c}_{\mathrm{p}} .
$$

Solving for $\dot{p}$ yields

$$
\dot{p}(x, y)-\left(y+c_{p}\right) /(x+y)<1 \text {. }
$$

where the inequality follows from the assumption that $x>c_{p}$. We will refer to $\dot{p}(x, y)$ as the "critical probability of prevailing."

The extent to which the defendant is deterred is determined by his

3 We assume without loss of generality that a victim will not sue if $p=\dot{p}(x, y)$. 
expected payment to the plaintiff plus his trial cost. Let $D(x, y)=1$ level of deterrence achieved given $x$ and $y$,

and observe that

$$
D(x, y)=\int_{\frac{p}{1}}^{1}\left[V(p, x, y)+c_{d}\right] f(p) d p
$$

Also, let

$$
L(x, y) \text { - level of litigation costs given } x \text { and } y \text {, }
$$

and note that

$$
L(x, y)-\int_{\hat{p}}^{1}\left(c_{p}+c_{d}\right) f(p) d p
$$

In general, social welfare includes the gain to the defendant from engaging in the harmful conduct, the harm to the plaintiff, and the litigation costs borne by both parties. For our purposes, however, it is not necessary to derive the optimal award and penalty from the maximization of social welfare. We simply want to show that if the award is positive and the penalty is zero, it always is possible to increase social welfare by raising both the award and the penalty. We will do this by demonstrating that a higher award and penalty combination can be chosen that achieves the same degree of deterrence of the defendant .. and therefore the same gain to the defendant and the same harm to the plaintiff - - but does so with lower litigation costs.

To be precise, if $x^{\prime}$ is any award when the penalty, $y$, is zero, we will show that there exists an $x^{\prime \prime}>x^{\prime}$ and a $y^{\prime \prime}>0$ such that $D\left(x^{\prime \prime}, y^{\prime \prime}\right)=D\left(x^{\prime}, 0\right)$ and $L\left(x^{\prime \prime}, y^{\prime \prime}\right)<L\left(x^{\prime}, 0\right)$.

As a preliminary matter, let $\dot{p}^{\prime}$ be the intelal value of the critical probability of prevailing (the value when $x-x^{\prime}$ and $y-0$ ):

$$
\dot{\mathrm{p}}^{\prime}-\dot{\mathrm{p}}\left(\mathrm{x}^{\prime}, 0\right)=c_{\mathrm{p}} / \mathrm{x}^{\prime} .
$$

Now define $y(x)$ to be the value of $y$ that solves $\dot{p}^{\prime} x-\left(1-\dot{p}^{\prime}\right) y=c_{p}$ for a 
given $x$; then

$$
y(x)=\left(\hat{p}^{\prime} x-c_{p}\right) /\left(1-\hat{p}^{\prime}\right)
$$

By construction, $\dot{p}(x, y(x))=\hat{p}^{\prime}$. In other words, for every combination of $x$ and $y(x)$. the value of the critical probability of prevailing is the same as the intial value. Hence, litigation costs are the same with $x$ and $y(x)$ as with $x^{\prime}$ and no penalty.

If $x=c_{p} / \hat{p}^{\prime}$, then from (6), $x=x^{\prime}$, and from $(7), y(x)=0$; in other words, starting with $x$ equal to $c_{p} / \dot{p}^{\prime}$ is equivalent to starting with $x^{\prime}$ and no penalty. Now substitute $y(x)$ for $y$ in $v(p, x, y)$ to get, using (1),

$$
\mathrm{V}(\mathrm{p}, \mathrm{x}, \mathrm{y}(\mathrm{x}))=\left[\left(\mathrm{p}-\dot{\mathrm{p}}^{\prime}\right) \mathrm{x}+(1-\mathrm{p}) \mathrm{c}_{\mathrm{p}}\right] /\left(1-\dot{\mathrm{p}}^{\prime}\right) \text {. }
$$

It is clear from (8) that for all $p>\hat{p}^{\prime}, V$ is strictly increasing in $x$.

Thus, if $x$ is raised above $c_{p} / \hat{p}^{\prime}$, say to some $x^{\prime \prime}$, and the penalty is set equal to $y\left(x^{\prime \prime}\right)$, then $V\left(p, x^{\prime \prime}, y\left(x^{\prime \prime}\right)\right)>V\left(p, x^{\prime}, 0\right)$ for all $p>\hat{p}^{\prime} .4$ Since the critical probability of prevailing remains at $\dot{p}^{\prime}$, it follows from (4) that deterrence will have risen above the initial level - that is, $D\left(x^{\prime \prime}, y\left(x^{\prime \prime}\right)\right)>D\left(x^{\prime}, 0\right)$. Note also that $y\left(x^{\prime \prime}\right)>0$ since, from $(7), y(x)$ is strictly increasing in $x$.

To restore deterrence to the initial level, keep $x$ equal to $x^{\prime \prime}$ and raise $y$ above $y\left(x^{\prime \prime}\right)$, to some $y^{\prime \prime}$, unt 11 deterrence falls to $D\left(x^{\prime}, 0\right)$. That deterrence declines as the penalty rises is clear since $V$ is strictly decreasing in $y$ and $\dot{p}$ is strictly increasing in $y .^{5}$ Moreover, as $y \rightarrow \infty$, $\mathrm{V} \rightarrow-\infty$ for all $\mathrm{p}<1$ and $\hat{\mathrm{p}} \rightarrow 1$, implying that deterrence must approach zero

4 To focus on the logic of the argument, we 1 gnore constraints (such as the defendant's or the plaintiff's wealth or considerations of fairness) that might prevent the award or the penalty from being raised to the desired level.

5 It is obvious from (1) that $V$ is strictly decreasing in $y$. From (3), $\partial \dot{\mathrm{p}} / \partial \mathrm{y}=\left(\mathrm{x}-c_{\mathrm{p}}\right) /(\mathrm{x}+\mathrm{y})^{2}>0$. 
(essentially no one sues). Thus, assuming continuity, there exists a $y^{\prime \prime}>$ $y\left(x^{\prime \prime}\right)>0$ such that $D\left(x^{\prime \prime}, y^{\prime \prime}\right)-D\left(x^{\prime}, 0\right)$. And since $\dot{p}$ is strictly increasing in $y_{,} L\left(x^{\prime \prime}, y^{\prime \prime}\right)<L\left(x^{\prime}, 0\right)$. This establishes the desired result. ${ }^{6}$

The reason it is possible to raise the award and the penalty so as to discourage suits without reducing deterrence is, in essence, because potential plaintiffs whose probability of prevailing is sufficiently high are favorably affected by these changes, while potential plaintiffs whose probability is relatively low are adversely affected. The former group benefits because the expected value of the increase in the award more than offsets the expected value of the increase in the penalty; the latter group suffers for the opposite reason. It is the detrimental effect on the latter group that causes fewer suits to be brought, while the beneficial effect on the former group allows deterrence to be maintained.

To appreciate the advantage of imposing a penalty on losing plaintiffs, consider the following numerical example. Let there be two potential plaintiffs, one with a probability of prevailing of 0.3 and the other with a probability of 0.8 . Each is equally likely to be injured. If a suit is filed, both the plaintiff and the defendant incur $\$ 20,000$ in trial costs. Suppose initially that the award to a winning plaintiff is $\$ 100,000$ and that there is no penalty imposed on a losing plaintiff. Given these values, both the low-probability and the high-probability plaintiff will sue if injured, the level of deterrence achieved against the defendant is $\$ 75,000$, and

6 It should be clear from the structure of this argument that social welfare can be increased by raising the award and the penalty starting from any award and penalty combination. We started with a positive award and a penalty of zero because this most closely reflects the conventional practice in the United States. 
litigation costs are $\$ 40,000 .^{7}$ It is easily shown that raising the award to a winning plaintiff from $\$ 100,000$ to $\$ 174,000$ and imposing a penalty of $\$ 46,000$ on a losing plaintiff will lead only the high-probability plaintiff to sue, will achieve the same level of deterrence against the defendant, and will reduce litigation costs by half, to $\$ 20,000$.

\section{Settlements}

This section extends the analysis of the previous section to a model in which settlements are possible.

The following sequence of events is assumed to occur. First, the victim decides whether to file a suit. Second, if a suit is filed, the defendant makes a single take-it-or-leave-it settlement offer (a refusal to settle corresponds to an offer of zero). 9 Third, the plaintiff decides whether to accept the defendant's offer or to go to trial.

Let

7 The low-probability plaintiff will sue because . $3 \times \$ 100,000=\$ 30,000$ $>\$ 20,000$; the high-probability plaintiff has an even stronger motive to sue. The level of deterrence achieved against the defendant is $.5[(.3 \times \$ 100,000)+$ $\$ 20,000]+.5[(.8 \times \$ 100,000)+\$ 20,000)-\$ 75,000$. Litigation costs are $\$ 40,000$ (the sum of the plaintiff's and the defendant's trial costs) because a suit will result whenever harm occurs.

8 The low-probability plaintiff now will be indifferent between suing and not suing because $(.3 \times \$ 174,000)-(.7 \times \$ 46,000)-\$ 20,000$ (the penalty could be raised by a dollar to make him strictly prefer to not sue). The high-probability plaintiff obviously then will have a positive motive to sue. The level of deterrence achieved against the defendant is $.5((.8 \times \$ 174,000)-$ $(.2 \times \$ 46,000)+\$ 20,000]-\$ 75,000$. Litigation costs now are $.5 \times \$ 40,000=$ $\$ 20,000$.

9 We assume that the defendant (the uninformed party) makes a settlement offer in order to avoid the "signalling" complications that would arise if the plaintiff (the informed party) made a settlement demand - the magnitude of the demand might convey information to the defendant about the plaintiff's type. 
$s$ - settlement offer of the defendant.

For notational simplicity, we will not indicate explicitly that the defendant's choice of $s$ depends on $x$ and $y$. Since a plaintiff whose probability of prevalling equals unity would obtain a net benefit of $x-c_{p}$ from going to trial, and all other plaintiffs would obtain less, this is the highest settlement offer the defendant would make. Thus,

$$
0 \leq s \leq x-c_{p}
$$

We assume for simplicity that it is costless to file a suit. Consequently, a victim will file a suit regardless of his probability of prevailing at trial since if the defendant offers any positive settlement, filing a suit and accepting the settlement offer is preferable to not filing the suit.

If the plaintiff accepts the defendant's offer, he obtains s; if he rejects it, his expected payoff at trial is px - (1 - p)y - $c_{p}$. Obviously, if $p$ is low enough, the plaintiff will accept the settlement offer. Let

$$
\tilde{p}(x, y) \text { - value of the probability of prevailing below which }
$$

a plaintiff will accept the settlement offer and above which he will go to trial,

where $\vec{p}(x, y)$ is defined by:

$$
\hat{p} \mathbf{x}-(1-\bar{p}) y-c_{p}=s .
$$

Solving for $\tilde{\mathrm{p}}$ yields

$$
\dot{p}(x, y)=\left(s+y+c_{p}\right) /(x+y) \leq 1 ;
$$

the inequality follows from (9). We will refer to $\vec{p}(x, y)$ as the "critical probability of prevailing." 10

10 Although this phrase was used to refer to $\dot{p}$ in Section 2 , it is employed here as well since $\dot{p}$ plays an analogous role and $\dot{p}$ will not be referred to in section 3 . 
Given the defendant's choice of the settlement offer, the level of deterrence achieved is

$$
D(x, y)-\int_{0}^{\bar{p}} \mathbf{s} f(p) d p+\int_{\bar{p}}^{1}\left[V(p, x, y)+c_{d}\right] f(p) d p,
$$

and litigation costs are

$$
L(x, y)-\int_{\tilde{p}}^{1}\left(c_{p}+c_{d}\right) f(p) d p .
$$

As in Section 2, we will show that if $x^{\prime}$ is any award when the penalty is zero, there exists an $x^{\prime \prime}>x^{\prime}$ and a $y^{\prime \prime}>0$ such that $D\left(x^{\prime \prime}, y^{\prime \prime}\right)=D\left(x^{\prime}, 0\right)$ and $L\left(x^{\prime \prime}, y^{\prime \prime}\right)<L\left(x^{\prime}, 0\right)$. This result is more difficult to demonstrate here because deterrence results in part from settlement payments and the defendant's choice of $s$ changes as $x$ and $y$ change. The structure of the proof, however, parallels that in Section 2.

Let $s^{\prime}$ be the settlement offer chosen by the defendant when the award is $x^{\prime}$ and there is no penalty. We assume that

$$
\mathbf{s}^{\prime}<\mathbf{x}^{\prime}-\mathrm{c}_{\mathrm{p}}
$$

otherwise (if $s^{\prime}-x^{\prime}-c_{p}$ ), all plaintiffs would accept the settlement offer initially and it would be impossible to lower litigation costs further.

Let $\bar{p}$ be the initial value of the critical probability of prevailing:

$$
\tilde{p}^{\prime}-\hat{p}\left(x^{\prime}, 0\right)-\left(s^{\prime}+c_{p}\right) / x^{\prime}<1,
$$

where the inequality follows from (14).

Define $y(x)$ to be

$$
y(x)-\left(\bar{p}^{\prime} x-c_{p}\right) /\left(1-\bar{p}^{\prime}\right) .
$$

It is easy to verify that

$$
\tilde{p}(x, y(x))-\tilde{p}^{\prime}+\left[\left(1-\tilde{p}^{\prime}\right) /\left(x-c_{p}\right)\right] s \geq \tilde{p}^{\prime} .
$$

Thus, for every $x$ and $y(x)$, the value of the critical probability of 
prevailing is no less than the initial value.

We will next show that there exists an $x^{\prime \prime}>x^{\prime}$ and a $y\left(x^{\prime \prime}\right)>0$ such that $D\left(x^{\prime \prime}, y\left(x^{\prime \prime}\right)\right)>D\left(x^{\prime}, 0\right)$. Starting from $x-c_{p} / \tilde{p}^{\prime}$, in which case $y(x)-0$, let $x$ grow without bound. First suppose that $\tilde{p}(x, y(x)) \rightarrow 1$ as $x \rightarrow \infty$; then it must be that $s \rightarrow \infty$ as well (otherwise, from (17), it is clear that $\bar{p}$ would approach $\hat{\mathrm{p}}^{\prime}<1$ ). Therefore, the first integral in (12) increases without bound, implying that there exists an $x^{\prime \prime}>x^{\prime}$ such that $D\left(x^{\prime \prime}, y\left(x^{\prime \prime}\right)\right)>$ $D\left(x^{\prime}, 0\right)$; and since $y(x)$ is increasing in $x$, clearly $y\left(x^{\prime \prime}\right)>0$.

Alternatively, if $\bar{p}$ does not approach unity as $x \rightarrow \infty$, then there exists an $\epsilon>0$ and some arbitrarily large $x^{*}$, say $x^{\circ}$, such that $\bar{p}\left(x^{0}, y\left(x^{0}\right)\right)<1-\epsilon$. Since

$$
V(p, x, y(x))=\left[\left(p-\tilde{p}^{\prime}\right) x+(1-p) c_{p}\right\} /\left(1-\tilde{p}^{\prime}\right)
$$

grows without bound in $x$ for all $p>\tilde{p}^{\prime}$, it follows that the second integral in (12) can be made arbitrarily large." Hence, again there exists an $x^{\prime \prime}>x^{\prime}$ such that $D\left(x^{\prime \prime}, y\left(x^{\prime \prime}\right)\right)>D\left(x^{\prime}, 0\right)$ and $y\left(x^{\prime \prime}\right)>0$.

Next, keeping $x$ equal to $x^{\prime \prime}$, raise $y$ above $y\left(x^{\prime \prime}\right)$ until deterrence falls to $D\left(x^{\prime}, 0\right)$, To see that this can be done, first note that as $y \rightarrow \infty, V \rightarrow-\infty$ for all $p<1$ and $\bar{p} \rightarrow 1$. This implies that if $y$ is high enough, the defendant will choose $s=0$. For if a positive $s$ is chosen, the defendant's costs are at least $s$ (everyone will file suit and at a minimum collect the settlement offer), whereas if $s=0$, the defendant's costs approach zero as $y \rightarrow \infty$ (since the probability of suit goes to zero and the cost to the defendant of being sued declines with $y$ ). Hence, deterrence must approach zero as $y \rightarrow \infty$, implying (assuming continuity) that there exists a $y^{\prime \prime}>y\left(x^{\prime \prime}\right)>0$ such that

11 That $\mathrm{p}>\overline{\mathrm{p}}$ ' over the range of integration in the second integral in (12) follows from (17). 
$D\left(x^{\prime \prime}, y^{\prime \prime}\right)=D\left(x^{\prime}, 0\right)$.

Finally, it remains to be shown that litigation costs fall. First observe from (11) that $\bar{p}(x, y)$ can be written as

$$
\tilde{\mathrm{p}}(\mathrm{x}, \mathrm{y})=[\mathbf{s} /(\mathrm{x}+\mathrm{y})]+\left[\left(\mathrm{y}+\mathrm{c}_{\mathrm{p}}\right) /(\mathrm{x}+\mathrm{y})\right] .
$$

By construction, for every $x$ and $y(x)$ combination, the second term in brackets equals $\overline{\mathrm{p}}^{\prime}$ (see (16)). Since this term is strictly increasing in $y$, when $x$ was held constant at $x^{\prime \prime}$ and $y$ was raised from $y\left(x^{\prime \prime}\right)$ to $y^{\prime \prime}$, the second term increased above $\bar{p}^{\prime}$. Moreover, the first term in brackets is non-negative. Thus, $\bar{p}\left(x^{\prime \prime}, y^{\prime \prime}\right)>\vec{p}^{\prime}$, which implies that $L\left(x^{\prime \prime}, y^{\prime \prime}\right)<L\left(x^{\prime}, 0\right)$ and completes the proof.

Although the analysis in this section is more complicated because of the possibility of settlements, the underlying intuition is similar to that discussed previously. Raising the award and the penalty benefits plaintiffs whose probability of prevailing is relatively high and disadvantages plaintiffs whose probability is relatively low. In Section 2 this had the effect of discouraging individuals in the latter group from filing suit, whereas here it discourages them from going to trial. In both instances, litigation costs fall as a consequence. Deterrence can be maintained, in Section 2 as well as here, because the expected value of the trial outcome is enhanced for the relatively high-probability-of-prevailing plaintiffs.

\section{Concluding Remarks}

This section explains how our analysis of optimal awards and penalties relates to the British rule for allocating litigation costs and to Becker's theory of public enforcement. 
(a) The British rule for allocating litigation costs. We assumed that each side paid for its own trial costs regardless of the outcome of the trial -. a practice commonly referred to as the American rule. An alternative is the British rule, under which the loser pays the winner's litigation costs. One could view a switch from the American rule to the British rule as a way of implementing the type of changes suggested in this article. Relative to the American rule, the British rule in effect increases the award to a winning plaintiff -- by the amount of the plaintiff's litigation costs - and also imposes a penalty on a losing plaintiff .. equal to the defendant's litigation costs. Thus, if the award otherwise cannot be varied and if the penalty otherwise would be zero, the British rule might be superior to the American rule for the reasons we discuss.

It is important to note, however, that neither the implicit award nor the implicit penalty under the British rule necessarily correspond closely to the optimal award and penalty. This can be seen in the numerical example. Recall that the plaintiff and the defendant each incurred trial costs of $\$ 20,000$. The award to a winning plaintiff was assumed to be $\$ 100,000$ when there was no penalty imposed on a losing plaintiff. Switching to the British rule would in effect raise the award to a winning plaintiff to $\$ 120,000$ and impose a penalty of $\$ 20,000$ on a losing plaintiff. Recall, however, that the optimal award was $\$ 174,000$ and the optimal penalty was $\$ 46,000$. Thus, in this example the optimal increase in the award is nearly four times the plaintiff's litigation costs and the optimal penalty is more than twice the defendant's litigation costs. ${ }^{12}$

12 Moreover, it is easily shown in this example that the implicit adjustments to the award and penalty under the British rule would not be enough to discourage low-probability plaintiffs from suing, whereas the 
(b) Becker's theory of public enforcement. Our analysis of optimal awards and penalties in private litigation has an obvious parallel to Becker's (1968) theory of optimal public enforcement. Becker showed that a higher fine allows the probability of detection to be lowered without sacrificing deterrence; enforcement costs are saved as a consequence. In private litigation, we have shown that a higher award and penalty can lead to a lower probability of suit or of trial without compromising deterrence; litigation costs are saved as a result. In both contexts, therefore, the sanction is raised, the probability of its imposition falls, and administrative costs are reduced.

It is well known that a logical implication of Becker's theory is that fines should be as high as possible and the probability of detection should be correspondingly low. Similarly, the logic of our analysis suggests that the award and the penalty should be as high as possible so that the probability of suit or of trial falls substantially.

Becker's theory has been criticized on the grounds that severe fines, potentially as high as an individual's wealth, hardly ever are imposed. An analogous criticism could be leveled against the implications of our analysis. In both contexts, however, there are additional considerations .. such as fairness or risk-bearing costs .. that, if taken into account, would lead to the conclusion that the optimal fine or the optimal award or penalty is not as high as possible.

optimal award and penalty would deter such suits. 


\section{References}

Bebchuk, Lucian Arye, and Howard F. Chang, "An Economic Analysis of Rule 11 and Fee-Shifting Based on the Margin of Victory," unpublished manuscript, Harvard Law School, May 1992.

Becker, Gary S., "Crime and Punishment: An Economic Approach," Journal of Political Economy, Vol. 76, No. 2 (March/April 1968), pp. 169-217.

Gravelle, Hugh S. E., "The Efficiency Implications of Cost-Shifting Rules," International Review of Law and Economics, Vol. 13, No. 1 (March 1993), pp. 3-27.

Katz, Avery, "The Effect of Frivolous Lawsuits on the Settlement of Litigation," International Review of Law and Economics, Vo1. 10, No. 1 (May 1990), pp. 3-27.

Polinsky, A. Mitchell, and Daniel L, Rubinfeld, "Sanctioning Frivolous Suits: An Economic Analysis," Georgetown Law Journal, forthcoming 1993. 